Nunt. Antiquus, Belo Horizonte, v. 15, n. 2, p. 11-25, 2019

\title{
Medeia e a rede de conectividade entre a região bárbara da Cólquida e a civilidade de Atenas no período clássico
}

\author{
Medea and the Network of Connectivity Between \\ the Barbarian Region of Colquida and the Civility \\ of Athens in the Classical Period
}

\author{
Maria Regina Candido \\ Universidade do Estado do Rio de Janeiro (UERJ), Rio de Janeiro, Rio de Janeiro / Brasil \\ medeiacandido@gmail.com
}

Resumo: Neste ensaio, nos propomos a analisar, através da dramaturgia de Medeia, do poeta Eurípides, as citações que nos despertam a atenção para a conectividade marítima entre o Mar Negro e as regiões gregas banhadas pelos mares Mediterrâneo e Egeu, consideradas áreas que detêm uma longa história de contatos e migrações. A dramaturgia de Medeia nos aponta para o processo de conectividade dos gregos em diferentes regiões do mundo antigo. Entretanto, esta conexão marítima detém a peculiaridade de ser a da região do Mar Negro menos conhecida do universo acadêmico do Ocidente. Podemos afirmar a escassez e a ausência de análise (sobre esta região), realizada por nós, pesquisadores da historiografia que estão na América Latina.

Palavras-chave: Medeia; conectividade marítima; Mar Negro; helenos; bárbaros.

Abstract: In this essay, we propose to analyze, through Euripides' Medea, the quotes that draw our attention to the maritime connectivity between the Black Sea and the Greek regions bordering the Mediterranean and Aegean seas, considered areas that have a long history of contacts and migrations. Medea's dramaturgy draws our attention to the process of connectivity between Greeks in different regions of the ancient world. However, this maritime connection has the peculiarity of being of the least studied, and therefore known, aspect of the Black Sea Region's History in the Western Academic Universe. We can attest to both the scarcity and the lack of analyses performed by us, historiography researchers in Latin America.

Keywords: Medea; maritime connectivity; Black Sea; Hellenes; barbarians. 
O poeta Eurípides inicia a dramaturgia de Medeia, representada no Teatro de Dioniso em Atenas no período de 431 a.C., citando, a saber: "nunca houvesse voado o barco de Argo à Cólquida pelas negras águas de Simplégades." (EURIPIDES, 1991, v. 2) e o navegador Pseudo-Scylax ${ }^{1}$ traz à memória dos gregos que "a grande região bárbara (pólis megále barbáron/Cólquida) foi o lugar de onde veio Medeia" (Pseudo-Skylax. 81.). As citações dos autores nos despertam a atenção para a conectividade marítima entre o Mar Negro e as regiões gregas banhadas pelos mares Mediterrâneo e Egeu, consideradas áreas que detêm uma longa história de contatos e migrações. A narrativa mítica deixa transparecer que o estreito marítimo permitia a passagem de embarcações de forma momentânea, esmagando qualquer objeto que tentasse transpor o pequeno atalho entre elas, fato que resultou no termo Simplégades, ${ }^{2}$ ou seja, Rochas das Colisões. Jasão e os Argonautas, com a ajuda dos deuses, remaram com vigor e passaram a salvo pelo estreito antes da colisão das ilhas. Remaram em direção ao litoral situado na extremidade oriental do mar e desembarcaram no reino de Cólquida (KAPPLER, 2004, p. 114).

O processo de migração ática para a região da Cólquida, situada no Mar Negro, no período clássico foi narrada por Heródoto ao mencionar o contato cultural e a geografia da região, cujo valor econômico centravase em torno do rio Fásis (Heródoto, III: 93). ${ }^{3}$ Péricles navegou diversas

${ }^{1} \mathrm{O}$ Periplous de Pseudo-Skylax descreve a circunavegação em torno dos Mares Mediterrâneo, Egeu e Negro passando pela Ibéria (Cólquida) e terminando o circuito na Coluna de Hércules na África. Os dados desta navegação sobreviveram a partir de anotações de Marciano de Heracleia, do VI a.C. e copilados no V e IV a.C. Devido ao desconhecimento do autor no período clássico e helenístico, a obra ficou intitulada Períplous de Pseudo-Skylax. A pesquisadora Shipley Graham (2011) mantém-se como especialista no tema e revisora dos fragmentos da obra no livro Pseudo-Skylax's Periplous: The Circumnavigation of the Inhabited World.

${ }^{2} \mathrm{O}$ escritor Filostrato, o jovem, no III sec. muito tempo depois menciona que a nau dos Argonautas carregava os cinquenta heróis pelo rio Fásis após passar pela região do Bósforo e pelo estreito das Simplégades/Clashing Rocks (PHILOSTRATUS the Younger, Imagines 8).

${ }^{3}$ Heródoto, nos livros III e IV nos traz informações sobre os habitantes da região da Cólquida (IV, 37; VI, 40) e sobre o rio Fásis que deságua no Mar Negro (IV, 37; IV, 45; VI, 38). 
vezes pela região com uma frota naval a partir de 437 a.C., visando ratificar a conectividade comercial e econômica da região de Atenas com os entrepostos comerciais estabelecidos junto aos cólquidos (Plutarco, Péricles: 24). Xenofonte, na obra Anábasis (7.1.29), nos fornece dados sobre a urbanização em torno do Mar Negro, informações provenientes de sua estada na região (KVIRKVELIA, 2005, p. 34), quando manteve relação de philía com grupos de famílias áticas e de cólquidos assentados na região (FAUDOT, 2005, p. 108).

A visibilidade da região, entre os atenienses, ocorreu quando Eurípides trouxe para o Teatro de Dioniso, em 455, a dramaturgia de Pelíades e em 431 a.C., a tragédia Medeia. Consideramos que o poeta trouxe à memória dos atenienses e demais gregos a narrativa mítica do "Velo de Ouro", cujo tema foi representado pelos artesãos-ceramistas nos vasos lékythoi e cotejado também nas entrelinhas da dramaturgia. Partimos do princípio de que o teatro de Atenas e os vasos áticos configuram-se como lugares de memória e de registros vivenciados por parte dos indivíduos que a eternizaram em imagem e texto como referências e cenários de visitas ao passado. Assim, os lugares de memória, segundo P. Nora, tornaram-se lugares, com efeito, nos três sentidos da palavra, material, simbólico e funcional [...] (NORA, 1993, p. 21). Mesmo em um lugar de aparência puramente material, como o espaço físico do teatro grego, as imagens de vasos e o texto da dramaturgia escrita somente tornam-se lugar de memória se a imaginação do pesquisador assim o investir, decodificar o seu simbolismo e estabelecer um sentido.

A dramaturgia de Medeia nos aponta para o processo de conectividade dos gregos em diferentes regiões do mundo antigo. ${ }^{4}$ Entretanto, esta conexão marítima detém a peculiaridade de ser a da região do Mar Negro menos conhecida do universo acadêmico do Ocidente. Podemos afirmar a escassez e ausência de análise (sobre esta

\footnotetext{
${ }^{4}$ A pesquisa de doutoramento (2013-2017) de Alessandra Viegas do PPGHC/UFRJ tem como tema Alimentação no Mundo Antigo: A paródia de Matro de Pitane e a recepção no IV a.C., na qual traz para o universo ático a culinária pesqueira de diferentes emporia gregos que transitavam nos banquetes em Atenas.
} 
região), realizadas por nós, pesquisadores da historiografia que estão na América Latina. Logo, cabe-nos trazer para o conhecimento do mundo acadêmico latino-americano os pesquisadores russos que escrevem em língua inglesa como Otan D. Lordkipanidze, Gocha R. Tsetskhladze ${ }^{5}$ e os recentes pesquisadores como Valentina Yanko-Hombach, ${ }^{6}$ Pavel M. Dolukhanov $^{7}$ e Anna A. Trofimova. ${ }^{8}$

Eurípides menciona que Medeia provém da região da Cólquida, região formada por um conjunto de póleis bárbaras como Trapezus, Dioscurias, Phasis e Pichvnari, cidades que emergiram como um centro de trocas comerciais e mercantis/emporium cuja dinâmica comercial despontou no período arcaico e clássico. Entretanto, o poeta não especifica de qual pólis bárbara a princesa seria proveniente. Fato que nos leva a trazer para o primeiro plano a região da Cólquida, região considerada pólis bárbara com abundância de terras férteis, de madeira, de grãos e de ouro, cuja documentação detém farta referência.

Cabe perguntar, onde fica a região da Cólquida (ou Colchis)? Analisando o mapa da região, torna-se perceptível que a região da Cólquida se situa no Ponto Euxino. ${ }^{9}$ O geógrafo Estrabão deixa transparecer que os gregos foram os primeiros estrangeiros que chegaram à região, a área era desabitada e totalmente desconhecida, e eles se depararam com as águas turvas e revoltas do Mar Negro (ESTRABON,VII,6,2).

${ }^{5}$ TSETSKHLADZE, G. R. An Account of Greek Colonies and Other Settlements Overseas, v. 1 (2006); v. 2 (2008); TSETSKHLADZE, G. R.; De ANGELIS, F. (ed.). The Archaeology of Greek Colonisation. Essays dedicated to Sir John Boardman (1994). TSETSKHLADZE, G, R.; SNODGRASS, A. M. (ed.). Greek Settlements in the Eastern Mediterranean and the Black Sea, (2002).

${ }^{6}$ YANKO-HOMBACH, V.; GILBERT, A. S.; PANIN, N.; DOLUKHANOV, P. M. (ed.). The Black Sea Flood Question: Changes in Coastline, Climate and Human Settlement. (2007).

${ }^{7}$ YANKO-HOMBACH, V.; GILBERT, A. S.; PANIN, N.; DOLUKHANOV, P. M. (ed.). The Black Sea Flood Question: Changes in Coastline, Climate and Human Settlement. (2007).

${ }^{8}$ TROFIMOVA, Anna A. (ed.). Greeks on the Black Sea: Ancient Art from the Hermitage (2007).

${ }^{9}$ Atestado por Píndaro na "Ode Pítica IV” (263). 
Diante das dificuldades de navegação, qualificaram a área como região inóspita ao estrangeiro, nomeando-a como Póntos Áxeinos (mar contra estrangeiros). Após o processo de ocupação da área e domínio de acesso pela navegação, os gregos renomearam a região como área hospitaleira - Póntos Eúxeinos (póntos = mar e eu/bom, e xeînos = estrangeiro, mar bom para estrangeiros) conhecido na atualidade como região do Mar Negro.

A região da Cólquida permanece como região mítica para nós, helenistas latino-americanos, mantendo o imaginário social misterioso de terra do Velo de Ouro e região da pharmakís Medeia. Cabe-nos trazer para o meio universitário brasileiro, visando à renovação historiográfica, os pesquisadores russos em diálogo com os ingleses e franceses; assim como o grupo de pesquisadores anglo-americanos, em parceria com helenistas russos, que realizaram a série de publicações online intitulada Greek on the Black Sea: Ancient Art from the Hermitage, e o British Institute at Ankara, responsável pelas pesquisas arqueológicas na região da Turquia e na região de Pichvnari, no Mar Negro. A região na atualidade configurase com a República Soviética da Geórgia e o interesse de pesquisadores sobre a presença dos gregos na região prevaleceu, nos seus primórdios, com a historiografia russa do século XX, com destaque para Otan D. Lordkipanidze e Gocha R. Tsetskhladze, ambos especialistas na região da Cólquida.

Outro dado importante que nós detectamos refere-se à região que se tornara área de interesse e de influência de Atenas. Fato que nos leva a refletir sobre as análises que identifiquem quais foram as estratégias de favorecimentos de trocas comerciais e mercantis e da possibilidade da relação: exportação de vasos áticos com vinho e azeite em troca de madeira, grãos e/ou metais. Para Anna M. Ckonia, a presença do ouro na região tem sido considerada como uma das forças motrizes que impulsionou o processo de migração dos gregos áticos para a região da Cólquida. A região ficou conhecida na Antiguidade como "região rica em ouro", e na Modernidade como "terra clássica do ouro", cuja narrativa mítica de Jasão no episódio do "Velo de Ouro" simbolizou a riqueza aurífera e o interesse ático pela região (CKONIA, 2002, p. 263; 
FAUDOT, 2005, p. 66). A exposição mítica do "Velo de Ouro" mantém estreita relação com o mito das Pelíades que relata o episódio da morte do rei Pélias, de Iolcos. O relato foi fornecido por Apolodoro (I, IX: 27), Higino (v. 24) e Pausânias (VIII, XI: 2), a narrativa mítica que compõe a ação mágica de rejuvenescimento de Pélias (ou Jasão), faz parte da dramaturgia construída por Eurípides, representada em 445 a.C., porém a peça se encontra perdida para nós. Entretanto, a narrativa mítica manteve-se no imaginário social do usuário/consumidor que solicita a materialidade do tema através da representação imagética em vasos áticos de figuras negras e vermelhas, ação que remontou ao VI a.C., intitulada de Medeia e o Carneiro ou Pelíades ${ }^{10}$ ou As filhas de Pélias.

Em relação à riqueza de cereais da região do Mar Negro que resultou em transporte de grãos para a Ática, nos reportamos a Heródoto (VII, 147) ao relatar a passagem de navios através do Mar Negro em direção à Grécia. T. S. Noonan trouxe a perspectiva da exportação de grãos do Mar Negro para a Grécia, mencionada pela documentação antiga, ao considerar a região como "celeiro de Atenas" (NOONAN, 1973, p. 231). O tema traz o questionamento sobre a escassez de alimento na Ática no periodo clássico. O debate começou com Thomas S. Noonan (1973), seguido por Gocha R. Tsetskhladze (1999), e foi retomado por Amiran Kakhdidze (2001). A historiografia soviética detém numerosos estudos clássicos sobre o comércio de grãos do Mar Negro para o mundo grego como I. B. Brashinski na obra Afiny i Severnoe Prichernomor'e v VI-VII vv. do n.e. (Moscou, 1963) que analisa os grãos do Bosfóro exportados para Atenas e considera a região do Bosfóro como celeiro de Atenas. David Braund (2007, p. 42) considera que o porto do Pireu se

${ }^{10}$ Em relação ao conjunto de vasos de cerâmica do período clássico e helenístico, analisamos 5 vasos com o tema "Velo de Ouro" (Jasão) e 25 vasos para as Pelíades ou Medeia e o Carneiro, no qual a sacerdotisa de Hécate aparece realizando os procedimentos mágicos de rejuvenescimento do idoso rei Pélias, que resultou em sua morte (ou não). Os temas formam o corpus iconográfico de Medeia no qual realizamos a catalogação e aplicação da grade metodológica, formulada por nós, a partir da obra de Claude Berard (Paris, 1983). As imagens com a metodologia aplicada constam do anexo do Relatório do Prociência/FAPERJ/UERJ 2014-2017. 
tornou, no período clássico, um grande foco de poder e riqueza, devido às intensas trocas comerciais e mercantis com o Mar Negro.

A partir desta constatação, podemos afirmar a existência de um modelo de interação e de intercâmbio sociocultural estabelecido pelos gregos na região considerada de natureza bárbara. Partimos do princípio que um grupo de atenienses de recursos financiou o khoregós ${ }^{11}$ patrocinador da dramaturgia de Medeia de Eurípides, cujo objetivo era incentivar o interesse dos atenienses no processo de migração para a região visando ao estabelecimento de emporium/entreposto comercial e apoikíai/colônias. O poeta constrói, junto aos atenienses, o imaginário social helênico da região da Cólquida através das aventuras de Medeia. Eurípides deixa transparecer a defesa de interesse de um grupo que denominamos de hetaireía, no qual inserimos Péricles, que tinha o interesse em estabelecer e/ou manter o contato com a região da Cólquida.

Consideramos que os atenienses, presentes no teatro de Dioniso em Atenas, tinham noção de que a longínqua região da Cólquida ficava muito distante da área familiar do Mar Egeu. Alertamos que os gregos transitaram por sociedades muito além dos mares Mediterrâneo e Egeu, chegando até ao Mar Negro, como indicam a jornada da Odisseia e a expedição dos Argonautas. ${ }^{12}$ A historiografia ${ }^{13}$ nos aponta para os imigrantes provenientes da região de Mileto na Jônia ${ }^{14}$ que desde o século VIII já haviam estabelecido jornadas em direção ao Mar Negro. A região

${ }^{11} \mathrm{O}$ tema sobre o financiamento dos khoregoí em Atenas tornou-se objeto de doutoramento de Dolores Puga Alves de Souza, PPGHC/UFRJ, intitulado: As Disputas Políticas na arena do Teatro de Atenas: um estudo comparado das Hetaireias de Eurípides e de Aristófanes (411-405/4 a. c.) (2014-2017), orientada pela Profa. Maria Regina Candido.

${ }^{12} \mathrm{O}$ tema sobre a expedição dos Argonautas e a circulação pelo Mar Negro e Mediterrâneo tornou-se tema de pesquisa do Prof. Alair Figueiredo Duarte, como extensão do doutorado no PPGHC/UFRJ (2014-2017).

${ }^{13} \mathrm{O}$ pesquisador Thomas S. Nooman cita alguns autores como Johannes Hasebroek no livro Trade and Politics in ancient Greece (1970) e Moses I. Finley no livro Early Greece: The Bronze and Archaic (1970) entre outros, que consideram que a colonização grega em direção ao Mar Negro foi motivada pelo excedente populacional.

${ }^{14}$ Os jônios da região de Mileto fundaram Sínope no VIII a.C. 
da Cólquida tornou-se área de influência dos atenienses e mantiveram intercâmbio cultural e mercantil com as cidades litorâneas de Dioskurios, Gyenos e Fasis. O destaque fica com Pitchvnari cujo cemitério demonstra o intenso intercâmbio cultural com Atenas, cuja materialidade se expressa pelas cerâmicas áticas encontradas no local. ${ }^{15}$ A materialidade da ação pode ser cotejada através da fundação de santuários para a deusa Ártemis, deusa protetora dos milésios. Os santuários foram analisados por Norbert Ehrhardt no livro Milet und seine Kolonien (1983) no qual o autor nos traz as evidências arqueológicas do culto de Afrodite em Mileto e nas colônias. O pesquisador Allan M. Greaves no artigo "The Cult of Aphrodite in Miletos and Colonies" complementa a informação ao disponibilizar o mapa de localização dos santuários de Afrodite nas colônias de Mileto situados no Mar Negro (GREAVES, 2004, p. 29).

Os atenienses empreenderam em tempo tardio o mesmo processo de expansão marcado somente para o início do período clássico. Fato trazido através da narrativa de Plutarco ao mencionar o interesse de Péricles em comandar diversas expedições para a região do Mar Negro. Fica evidente que, a partir do período clássico, a presença da frota naval e a dinâmica do porto do Pireu apontaram para os atenienses a possibilidade ou a necessidade de buscar espaços alternativos às atividades agropastoris na Ática resultando na migração para a região da Cólquida. Partindo do princípio de que toda história é uma história contemporânea (CROCE, 1921 , p. 12), consideramos que as questões relacionadas ao processo de migração na Antiguidade foram construídas a partir da articulação com o tempo presente. $\mathrm{Na}$ atualidade, vivenciamos o deslocamento de populações de migrantes, que são alvo de violência, discriminação étnica e religiosa. ${ }^{16}$ Um dos centros da atenção tem sido o Mar Mediterrâneo

${ }^{15}$ Ver: O. D. Lordkipanise, “Ancient Colchis” (1979); M. Y. Treister; Y. G. Vinogradov, "Archaeology of the Northern Coast of Black Sea" (1993); D. Braund, "Georgia in Antiguity" (1994).

16 “"A perseguição, o conflito e a pobreza forçaram um milhão de pessoas a fugir para a Europa em 2015, algo sem precedentes', disse a OIM. Segundo a organização, mais de 800 mil cruzaram para a Grécia vindos da Turquia, incluindo mais de 455 mil imigrantes que partiram da Síria e mais 186 mil do Afeganistão. Cerca de 3.700 outros morreram tentando atravessar o mar Mediterrâneo na pior crise de refugiados que a Europa vive 
e as frágeis travessias realizadas pelas imediações das cidades gregas banhadas pelo Mar Egeu. A drástica situação nos traz à memória o pesquisador Adauto Novaes, ao afirmar que, poucas vezes, ao longo da história, o Ocidente viveu de forma tão trágica e explícita a confluência da civilização e da barbárie. Vivemos o descrédito da política, o desprezo das normas éticas e morais, a opacidade das relações sociais, cujo resultado nos leva a pensar que a astúcia do poder produz guerra em nome da paz (NOVAES, 2004, p. 7).

Stanley M. Burstein considera que a história dos gregos na região do Mar Negro tem sido escrita como processo de expansão do modo helênico de viver. Entretanto, a helenicidade ${ }^{17}$ dos contatos nas apoikiai e nos empórios ocorria no litoral de terras inseridas no universo de terras bárbaras (BURSTEIN, 2006, p. 137). Consideramos a ação como parte do intercâmbio cultural cujo resultado foi a helenização ou helenicidade de algumas regiões bárbaras do Mar Negro. Amiran Kakhidze considera que o aumento das atividades de trocas comerciais e mercantis foi motivado também pela necessidade cultural do binômio centro-periferia, ou seja, o recebimento de produtos do Mar Negro em Atenas tinha como contrapartida suprir a região periférica com produtos culturais provenientes da dinâmica Atenas (vasos de cerâmica ática, dramaturgia, festivais, vinho/azeite, entre outros) (KAKHIDZE, 2005, p. 117).

O processo de interação cultural com a vizinhança de cultura desconhecida dependia da negociação em diferentes níveis como as trocas materiais, casamentos e associações, entre outras estratégias que garantiam a sobrevivência e a proteção dos gregos na região. Eurípides coloca na voz de Jasão que "em lugar de região bárbara, ela [Medeia] passou a habitar terras gregas que conheciam a justiça e o uso das leis no lugar da força" (EURÍPIDES, 1991, v. 535-540). O poeta constrói

desde a Segunda Guerra Mundial." ("MAIS de um milhão de refugiados e imigrantes chegaram à Europa em 2015").

${ }^{17}$ A ação dos gregos ao expandir a cultura helênica no Mar Mediterrâneo e no Mar Negro tem sido nomeada como helenicidade por Kostas Vlassopoulos; helenismo foi o termo acadêmico oriundo da palavra grega hellenizein, que significa falar grego e se comportar como um grego. Johann-Gustav Droysen foi quem inseriu o termo no mundo acadêmico como sendo Hellenismus em 1836. 
a trajetória da protagonista como uma mulher que sai dos limites da barbárie da Cólquida para o centro da civilidade dos atenienses. Kostas Vlassopoulos afirma que a relação entre gregos e bárbaros faz parte de um amplo debate que parte da distinção geográfica entre o Ocidente versus o Oriente. Os gregos detêm a helenicidade, ${ }^{18}$ a cultura, a sociabilidade e tornaram-se referência no Ocidente, pois inventaram a democracia, a liberdade de expressão, a ciência, a filosofia e a dramaturgia, e o Oriente passou a ser a área dos povos considerados bárbaros (VLASSOPOULOS, 2013, p. 2).

Em seu lamento, Medeia relata todo o processo de chegada do jovem grego Jasão à região bárbara da Cólquida, assim como as suas aventuras e desafios, fato que nos faz lembrar a trajetória de grupos de atenienses que migraram para a região do Mar Negro. Tanto os jônios de Mileto quanto os atenienses construíram kleroukhíai, apoikíai e emporia, a ação nos conduz ao debate sobre a motivação para a saída dos gregos áticos em direção às terras consideradas inóspitas e bárbaras do Mar Negro.

No lugar da análise a partir do conceito de dominante e dominado ou da relação centro e periferia, nos aproximamos de uma vertente alternativa que traz à reflexão o contato relacional de convivência negociada e compartilhada que fomenta a ação de reciprocidade do dom e contra dom entre gregos/atenienses e não gregos. O processo de migração dos gregos/atenienses para o Mar Negro nos permite identificar a natureza dos pontos de conectividade (emporia, apoikíai, kleroukhíai) necessários como áreas de contato para reabastecimento e consertos de avarias nas embarcações. Esses pontos de conectividade formam a interligação entre o Mar Egeu e o Mar Negro, passando pelo Mar Mediterrâneo, definidos pela expedição dos Argonautas, que no conjunto constitui a rede de conectividade/network, como deixa transparecer a dramaturgia de Medeia e a circulação dos vasos áticos com imagem do "Velo de Ouro" e o conjunto Pelíades/Medeia e o Carneiro, que mantém relação com a abordagem mítica de Eurípides.

${ }^{18} \mathrm{O}$ fator-chave da formação da identidade grega, a helenicidade, está na narrativa de formação da maneira helênica de ser e no papel que ela exerce na formação do não grego. 
Em Atenas, a contrapartida nos aponta para a entrada de ritos estrangeiros ${ }^{19}$ e bárbaros, considerados como culto aos novos deuses sediados na região do porto do Pireu, como nos aponta Platão, ao mencionar o ato de Sócrates descer em direção ao porto, ou seja, katabaino eis Peiraia, para participar do culto estrangeiro da deusa Bentis introduzida pelos trácios entre os atenienses em 429 a. C (FOUCART, 1975, p. 131). Temos que considerar as associações voluntárias para culto às divindades estrangeiras situadas no porto do Pireu, formando thíasoi, éranoi e orgeónes com os quais interagiam homens e mulheres, atenienses, metecos, estrangeiros e escravos. Como deixa transparecer o Velho Oligarca, no século V, ao citar que os atenienses, em razão do domínio marítimo "misturaram-se com outras etnias e descobriram produtos de consumo variados... qualquer que seja o produto e onde quer que esteja, Sicília, Itália, Chipre, Egito, Lídia e no Mar Negro tudo vem para o mesmo ponto (porto do Pireu) em virtude do poder naval" (A constituição dos Atenienses, I:7). Complementamos com o diálogo de Sócrates, ao afirmar: "fui ontem ao Pireu com Glauco para orar à deusa (trácia Bentis) e para me certificar também de como seria a festividade" (Platão, República, II: 327a).

A constatação nos afasta da relação binária de oposição entre gregos e não gregos tanto na área do Pireu em Atenas quanto na região da Cólquida no Mar Negro e nos aproxima de conceitos relacionados à interação e intercâmbio sociocultural entre grupos de culturas distintas cuja proximidade foi proveniente da dinâmica da conectividade marítima do período clássico dos atenienses. As escavações arqueológicas apontam a presença de estelas de mármore, IG.II 2337, que evidenciam as solicitações dos mercadores citas no IV a.C, interessados na construção de um santuário dedicado a uma divindade estrangeira semelhante à deusa Afrodite Urânia. O solicitante menciona na epigrafia que deseja o

\footnotetext{
${ }^{19}$ A região do Porto do Pireu recebeu várias solicitações de citas, egípcios, trácios, para a construção de santuários para o culto das deusas Bentis, Ísis e Afrodite; ver a dissertação de Mestrado da pesquisadora Marina Rockenback de Almeida, intitulada Por um comparativismo construtivo do culto à Isis entre atenienses e egípcios no final do V sec aec. Defendida em 2016 no PPGHC/UFRJ.
} 
mesmo tratamento que foi concedido aos egípcios para a construção de santuário da deusa Ísis na região do Pireu (GARLAND, 1987, p. 337). A ação confirma a prática de intercâmbio sociocultural entre os atenienses e os estrangeiros considerados bárbaros e não somente o processo de expansão helenística em via de mão única.

Concluímos que nestas regiões longínquas, os gregos/atenienses não propuseram o estabelecimento de um pan-helenismo nem impetraram ações imperialistas ou de liderança unipolar na região. A documentação nos permite conjecturar sobre o estabelecimento de conectividade entre gregos/atenienses e não gregos, cujo resultado foi constatado através da transferência de seus cultos, crenças e mitos assim como a circulação de objetos, dramaturgias, linguagens poéticas que constituíram a rede de conectividade cultural. A criação de espaço relacional híbrido tornou-se possível a partir das redes de conectividade tanto em Atenas na região do porto do Pireu quanto na região que compõe as póleis bárbaras da Cólquida. A materialidade do tema passa a ser apreendida através da narrativa mítica de Medeia, a dramaturgia produzida por Eurípides. Incluímos o conjunto de vasos áticos com imagens relativas ao tema mítico que envolvem Medeia, Jasão e o "Velo de Ouro", temáticas que se tornaram constantes. Consideramos que a sociedade helênica pode ser pensada em termos de conectividades próximas e distantes. Os conceitos da Social Network Theory, traduzida por nós como Teoria da Conectividade Social, ${ }^{20}$ detêm como abordagem teórica a capacidade de aplicação em História Antiga, pois a rede de conectividade marítima fomentou a mobilização de atenienses, gregos e não gregos em direção ao Mar Negro desde o período arcaico. A ação resultou na formação de grupos de identidades diversas que compartilharam um interesse comum ao demarcar os pontos de conectividade (apoikíai, emporia, kleroukhíai) que margeiam o litoral do Mar Egeu, do Mediterrâneo e do Mar Negro.

\footnotetext{
${ }^{20} \mathrm{O}$ conceito de conectividade integra o universo da Social Network Theory, que traduzimos como "Teoria da Conectividade Social", e que capacita o pesquisador a explorar os aspectos relacionais de contatos promovidos entre grupos de natureza distinta, como os gregos com os não gregos. A partir desta conectividade emergem o partilhamento, a interação e o intercâmbio cultural, político, econômico, social e religioso.
} 
No estudo da antiguidade grega nas últimas décadas tem predominado a abordagem sobre pólis e temas relacionados como a polaridade da relação estrutural definida entre cidadão versus estrangeiros, homem versus mulher, cidadão livre versus escravo e a célebre relação binária de oposição entre gregos e bárbaros. A comunidade políade definese como a forma pela qual os gregos concebiam o conceito de pólis helênica, definida como koinonía, ou seja, associação de cidadãos gregos. Entretanto, o período clássico deixa transparecer a emergência de diferentes comunidades e associações que teceram a proximidade entre gregos, estrangeiros e bárbaros, situadas em regiões litorâneas de Atenas, no Mar Egeu, e da Cólquida, no Mar Negro.

\section{Referências}

ARISTOTLE. Constitution d'Athènes. Tradução de G. Mathie. Paris: Les Belles Lettres, 1996.

BRAUND, David. Art and Archaeology. The Greeks in the East. London: British Museum Press, 2007.

BURSTEIN, Stanley M. The Greek Cities of the Black Sea. In: KINZL, Konrad H. (ed.). A Companion to the Classical Greek World. Oxford: Blackwell, 2006. p. 137-152. DOI: https://doi. org/10.1002/9780470996799.ch8

CKONIA, A. M. A propos de l'exportation de l'or colchidien. In: FAUDOT, M. (ed.). Pont-Euxin et Polis: Polis hellenis et Polis Barbaron. Besançon: Presses Universitaires de Franche-Comté, 2005. p. 263-272.

CROCE, Benedetto. History, Its Theory and Practice. New York: Cornell University, 1921.

CSAPO, Eric et alli. The Origins of Theater in Ancient Greece and Beyond: from Ritual to Drama. Cambridge; New York: Cambridge University Press, 2007.

EHRHARDT, N. Milet und seine Kolonien. Frankfurt am Main: P. Lang 1983.

ESTRABON. Geografia V-VII. Traducción de José Vela Teja y Jesus Gracias Artal. Madrid: Editorial Gredos, 2001. 
EURÍPIDES. Medeia. Tradução de Jaa Torrano. São Paulo: HUCITEC, 1991. Edição Bilíngue grego-português.

FAUDOT, M. (ed). Pont-Euxin et Polis: Polis hellenis et Polis Barbaron. Besançon: Presses Universitaires de Franche-Comté, 2005.

FOUCART, Paul François. Des Associations Religieuses chez les Grecs: Thiases, Éranes, Orgéons. Paris: Les Belles Lettres, 1975.

GARLAND, Robert. The Piraeus: from the Fifth to the First Century BC. London: Duckworth, 1987.

GRAHAM, Shipley (trad.). Pseudo-Skylax's Periplous: The Circumnavigation of the Inhabited World. Exeter: Bristol Phoenix, 2011.

GREAVES, Allan M. The Cult of Aphrodite in Miletos and Its Colonies. Anatolian Studies, Ankara, v. 54, p. 27-33, 2004. DOI: https://doi. org/10.1017/S0066154600000545.

HOPMAN, Marianne. Revenge and Mythopoiesis in Euripides' Medea. Transactions of the American Philological Association, Baltimore, v. 138, p. 155-183, 2008. DOI: https://doi.org/10.1353/apa.0.0002.

KAKHIDZE, A., IASHVILI. I., Vickers, M. Silver Coins of Black Sea Coastal Cities from the Fifth Century BC Necropolis at Pichvnari. The Numismatic Chronicle, London, v. 161, p. 282-288, 2001.

KAPPLER, Claude. Monstruos, demonios y maravillas a fines de la Edad Media. Madrid: AKAL, 2004.

KVIRKVELIA, Guram. Polis Barbaron in the Black Sea area in archaic and classical periods. In: FAUDOT, M. (ed.). Pont-Euxin et Polis: Polis hellenis et Polis Barbaron. Besançon: Presses Universitaires de FrancheComté, 2005. p. 33-40.

MAIS de 1 milhão de refugiados e imigrantes chegaram à Europa em 2015. Veja, São Paulo, 22 dez. 2015. Disponível em; https://veja.abril. com.br/mundo/mais-de-1-milhao-de-refugiados-e-imigrantes-chegarama-europa-em-2015/. Acesso em 22 out. 2016.

NOONAN, Thomas S. The Grain Trade of the Northern Black Sea in Antiguity. The American Journal of Philosophy, New York, v. 94, n. 3, p. 231-242, 1973. DOI: https://doi.org/10.2307/293978. Disponível em: https://www.jstor.org/stable/293978?seq=1. Acesso em: 10 fev. 2016. 
NORA, P. Entre memória e história: a problemática dos lugares. Trad. Yara Aun Khoury. Projeto História, São Paulo, v. 10, p. 7-28, 1993.

NOVAES, Adauto. Civilização \& barbárie. Rio de Janeiro: Companhia das Letras, 2004.

PHILOSTRATUS. Elder Philostratus, Younger Philostratus, Callistratus. Translated by Fairbanks. London: William Heinemann, 1931. (Loeb Classical Library, v. 256)

PLATÃO. República. Tradução de Maria Helena da Rocha Pereira. Lisboa: Fundação Calouste Gulbenkian,1993.

PLUTARCO. Vidas Paralelas: Péricles e Fábio Máximo. Tradução do grego por Ana Maria Guedes Ferreira e Ália Rosa Conceição Rodrigues. Coimbra: Imprensa da Universidade de Coimbra, 2010.

PSEUDO-SKYLAX'S PERIPLOUS: The Circumnavigation of the Inhabited World. Tradução de Shipley Grahan. Exeter: Bristol Phoenix, 2011.

ROBERTSON, Martin. The Art of Vase-Painting in Classical Athens. Cambridge: Cambridge University Press, 2000.

ROCKENBACK, Marina. Por um comparativismo construtivo do culto à Ísis entre atenienses e egípcios no final do V século AEC. Orientadora: Maria Regina Candido. 2016. 184f. Dissertação (Mestrado) - Instituto de História, Universidade Federal do Rio de Janeiro, Rio de Janeiro, 2016.

VELHO OLIGARCA. A Constituição dos atenienses. Tradução de Neyde Theml e André Chevitarese. Vitória: EDUFES, 2002.

VLASSOPOULOS, Kostas. Greeks and Barbarians. Cambridge: Cambridge University Press, 2013. DOI: https://doi.org/10.1017/ CBO9781139049368.

WILES, David. Tragedy in Athens, performance space and Theatrical meaning. Cambridge: Cambridge University Press, 1997. DOI: https:// doi.org/10.1017/CBO9780511582295.

Recebido em: 23 de agosto de 2019. Aprovado em: 5 de dezembro de 2019. 